\title{
Knowledge and Attitudes towards Proposed Graphic Warnings in a Set of Male Health Care Workers in the National Hospital of Sri Lanka
}

\author{
Rahubaddha A.N. 1,", Rajakaruna H.I. ${ }^{1}$, Rajakaruna P.A.S.Y. ${ }^{1}$, Jayasinghe S. ${ }^{2}$ \\ ${ }^{1}$ Faculty of Medicine, University of Colombo, Sri Lanka \\ ${ }^{2}$ Department of Clinical Medicine, Faculty of Medicine, University of Colombo, Sri Lanka
}

Copyright $\bigcirc 2016$ by authors, all rights reserved. Authors agree that this article remains permanently open access under the terms of the Creative Commons Attribution License 4.0 International License

\begin{abstract}
Introduction - The Sri Lankan government took measures to introduce new legislation to include graphic warnings covering $60 \%$ of the surface area of packets of cigarettes affecting from 1 January 2015. In this study we aimed to assess the knowledge and attitudes towards proposed graphic warnings on packets of cigarettes in a set of male health care workers. Method - An institution based cross sectional descriptive and analytical study was carried out in the National Hospital of Sri Lanka. The study population comprised of 119 semi-skilled workers who were selected via multi step simple random sampling. A self-administered questionnaire and samples of packets of cigarettes containing model pictorial warnings were used as study instruments. Results - Majority (63.21\%) of the study population were unable to recall the already existing text-only warning messages printed on packets of cigarettes. Majority $(89.47 \%)$ of the study population endorsed the view that the demonstrated sample pictorial warnings were effective in sending a stronger warning message to smokers than the prevailing text-only warnings. Majority $(80.39 \%)$ of the smokers thought that the demonstrated sample graphic warnings would have a negative impact on their smoking habits. Statistically significant amount of smokers than non-smokers thought that the proposed graphic warnings would have a negative impact on future smokers. Conclusions and recommendations - These findings provide strong support for introducing graphic warnings on packets of cigarettes. Proposed graphic warnings will most likely affect the smoking habits of the public and the smokers would be made more likely to contemplate quitting smoking. Such a shift in attitude in the population could be a major impetus to reduce the smoking rate. However retrospective studies are recommended after the introduction of the graphic warnings to assess their true impact.
\end{abstract}

Keywords Graphic Warnings, Tobacco, Smoking

\section{Introduction}

Background

Tobacco is the greatest single cause of preventable deaths globally according to WHO report, "Global Tobacco Epidemic" published in $2008^{(1)}$. Similarly the American Center for Disease Control and Prevention (CDC) describes tobacco use as the single most important preventable risk to the human health in developed countries and an important cause of premature deaths worldwide ${ }^{(2)}$. Several countries have taken measures to control the consumption of tobacco with usage and sales restrictions and warning messages printed on packages.

A spot survey carried out by Alcohol and Drug Information Centre (ADIC) in 2012 has revealed that in Sri Lanka $33.2 \%$ of male population above the age of 15 are smokers ${ }^{(3)}$. Tobacco use has been ranked as the number one major modifiable risk factor for non-communicable diseases by the report 'Prevention and control of selected chronic NCDs in Sri Lanka' by Michael Engelgu et all (4). Understanding the gravity of the problem, the Ministry of Health passed a regulation requiring tobacco products to contain graphic pictorial health warnings on $80 \%$ of the pack.

However this initiative is to be implemented from 1 January 2015 after a much publicized court case filed by the Ceylon Tobacco Company challenging the regulation ${ }^{(5)}$. Sri Lanka's Supreme Court ordered the country's leading tobacco product manufacturer, Ceylon Tobacco Company to cover 60 per cent of the front and back of cigarette packs with graphic health warnings ${ }^{(11)}$.

\section{Justification}

Tobacco is one of the major causes of deaths worldwide. Tobacco use kills 5.4 million people a year and an average of one person every six seconds accounting for one in ten adult deaths worldwide according to $\mathrm{WHO}^{\left({ }^{(6)}\right.}$. Its extensive 
harmfulness to general health has prompted the governments all over the world to restrict tobacco consumption by several means. These means have been laid out by the WHO Framework Convention on Tobacco Control ${ }^{(7)(8)}$. Inclusion of pictorial warnings on packets of cigarettes is one such action the governments have resorted to.

Studies show that in some countries the inclusion of graphic warnings has a negative impact on smokers as well as going to be smokers. In a few countries the results are inconclusive. In Sri Lanka the legislation to introduce the graphic warning on packets of cigarettes has been initiated by the Ministry of Health ${ }^{(9)}$.

Since the parliament of Sri Lanka passed the motion unanimously to include graphic warnings on packets of cigarettes $^{(10)}$, it has become one of the most discussed contemporary health topics in the country. This topic was chosen due to its timely importance and extensive implications with regard to public health of Sri Lanka.

General objective

Describe knowledge and attitudes towards proposed graphic warnings on packets of cigarettes

The Specific objectives

1. Assess the knowledge on existing printed warnings on packets of cigarettes

2. Assess the knowledge and attitudes on proposed graphic warnings on packets of cigarettes

3. Compare the difference in attitudes towards proposed graphic warning between smokers and non-smokers

\section{Literature Review}

The literature related to graphic warning on packets of cigarettes is reported in this chapter. The sources utilized for literature survey include medical library of Faculty of Medicine, Colombo and the world wide web where search engines such as Google scholar, Pub Med and HINARI were used to access to the articles pertaining to the topic. The search criteria included the key words "smoking", "pictorial warning", "packets of cigarettes" and "smokers and non-smokers". Time period used for the search criteria was 1990 to 2014.

For organizational purposes, the literature is presented under the following topics: (1) attitudes towards proposed graphic warning on packets of cigarettes, (2) difference in attitudes between smokers and nonsmoker, (3) summary.

Attitudes towards Proposed Graphic Warnings on Packets of Cigarettes

In a cross sectional research carried out in Australia in 1997 after the graphic warning was introduced in the country it was found to be that There was high awareness of the new warnings, particularly among smokers ${ }^{(12)}$. It was reported that one third of the smokers were affected by the new warnings and the same amount of smokers have reduced the consumption of cigarettes. It was concluded in the research that the results suggest the new health warnings have resulted in better informed smokers.

Another cross sectional research has been carried out in Thailand and Malaysia where a representative sample of 2,000 adult smokers from each country were recruited and followed up ${ }^{(13)}$. In this research the main focus was on cognitive and behavioral reactions to graphic warnings on packets of cigarettes. It was revealed that in Thailand the pictorial health warning labels have led to a greater impact than the text-only warning labels. However no significant changes were observed in the sample of Malaysian smokers in this regard.

Another study that was carried out in Thailand in 2008 where six hundred nine employees (both non- or smokers) were part of a cohort study using qualitative and quantitative approaches ${ }^{(14)}$. The study has shown that $3.8 \%$ stopped smoking after seeing the new graphic warnings. Moreover, the graphic warnings increased employees "pro" attitudes about smoking cessation.

Difference in Attitudes between Smokers and Nonsmokers.

In 2011, the Food and Drug Administration in the United States published a final rule requiring cigarette packets to include graphic health warning labels (HWLs). A study carried out in the United States with 4,236 participants, aged 18-34 using an online panel in January $2012^{(15)}$, it was reported that fifty-three percent of the participants endorsed that new graphic warnings make them think about not smoking. $40 \%$ of the current smokers in contrast to $56 \%$ of the non-smokers endorsed this view. Among nonsmokers, those aged 18-24, females, Hispanics, and those who were aware of graphic warnings were more likely to report intention to not smoke related to graphic warnings.

In another study carried out in the United States in 2010 under the topic of 'Nonsmoking Male Adolescents' Reactions to Cigarette Warnings', using a national sample of 386 non-smoking American males ages 11-17, it was observed that warnings discouraged most adolescents from wanting to smoke ${ }^{(16)}$. It was also observed that the graphic warnings focusing on lung cancers were more likely to discourage male adolescents from smoking than the text-only warnings on addiction.

\section{Summary}

In the studies that were reviewed during this exercise, the main focus was on the attitudes towards the graphic warnings on cigarette packets and especially the impact they have on the cessation of smoking. In all studies with the exception of the one carried out in Malaysia ${ }^{(13)}$ it was found out that the graphic warnings result in better informed smokers, improving the likelihood of cessation of smoking in them.

\section{Methodology}

Study Design 
An institution based cross sectional descriptive and analytical study.

\section{Study Setting}

National Hospital of Sri Lanka (NHSL).

Study Population

126

Inclusion Criteria - Male semi-skilled workers of NHSL.

Exclusion Criteria - Male semi-skilled workers who have been medically advised not to smoke.

\section{Sampling method}

Multi step simple random sampling. The National Hospital is subdivided in to sections for administrative purposes. Each section has an overseer whose responsibility is to maintain an attendance sheet ('check roll') of the semi-skilled workers and attendants. Three such sections were selected randomly. The total number of male semi-skilled workers amounted to 477. Out of these candidates 126 were selected randomly. As data was obtained by self-administered questionnaire, an allowance for error due to non-respondents was made for the calculation of the sample size.

\section{Study Instruments}

- Self-administered questionnaire - The questionnaire was prepared in English. Questionnaire was then translated in to Sinhala and Tamil by independent translators. This included close ended, structured questions.

- Samples of packets of cigarettes containing the model pictorial warnings - These samples were obtained by pasting pictorial warnings used in other countries $^{(17)}$, over the local packets of cigarettes. Special care was given to cover only $60 \%$ of the surface area. (See annex)

Study procedure

After the completion of study design; the information sheet, consent form and self-administered questionnaire were submitted to the Ethics Review Committee of Faculty of Medicine, Colombo and that of NHSL. We provided adequate information regarding the study and the method of data collection. Recruitment of participants to our study was done according to the inclusion and exclusion criteria.

Pre Test

The questionnaire was pre-tested to identify whether the options given were sufficient and appropriate. Pretesting was carried out on male semi-skilled workers from the sections that were not selected for the study proper, in keeping with the inclusion and exclusion criteria.

According to their feedback, suitable amendments were made to make the questionnaire more comprehensible and effective, before conducting the study proper.

Method of data collection
A brief introduction about the study was given to the participants on the day of data collection prior to administration of questionnaires. An information sheet was distributed along with the questionnaire to explain about the participant anonymity, confidentiality and voluntary nature of participation. Self-administered questionnaires were distributed to the participants. Samples of packets of cigarettes containing the model pictorial warnings were demonstrated during the interview.

Data analysis

Data was collected and analyzed using SPSS ver.21.0 software.

Ethical considerations

- Permission from Director of NHSL was obtained.

- Privacy was maintained as questionnaires did not contain any data for personal identification such as name and registration number.

- Even though this research does not have benefits to participants at individual level, it has a social value which would help in determining the knowledge and attitudes towards introduced pictorial warnings.

- The data obtained is kept under lock and key and will be destroyed after 6 months of data analysis.

- As the data collection method was non-invasive and by maintaining the confidentiality, minimum harm was done to any of the participants.

- Prior informed consent was taken from all participants.

- Findings from the study will be disseminated amongst the medical community and the public.

\section{Results and Analysis}

- Out of the 119 questionnaires collected 6 were rendered ineligible due to noncompliance with instructions. The 114 remaining respondents' questionnaires were analyzed using SPSS version 21. Out of these respondents 51 were smokers $(44.73 \%)$ while the remainders of 63 were non-smokers (55.27\%).

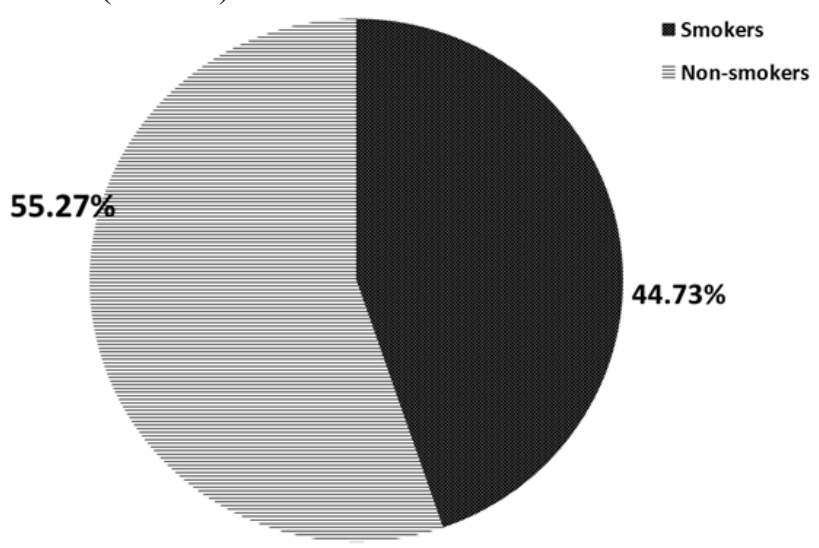

Figure 1. Graphical representation of the number of smokers and non-smokers among the interviewed. 
1. Knowledge on existing warning messages on packets of cigarettes

- Out of the 114 respondents, 107 (94.69\%) shared the view that they were aware of the pre-exsiting helath warnings printed on the packets of cigarettes. However only $39(36.79 \%)$ of them could identify the correct warning statement that is currently being printed on the packets of cigarettes in Sri Lanka.

2. Knowledge and attitudes on proposed graphic warnings on packets of cigarettes

- Majority of the respondents were aware of the government's decision to include pictorial warnings on packets of cigarettes. This number amounted to $104(92.03 \%)$ out of the 113 that had responded. Only 7 (7.93\%) were unaware of this development.

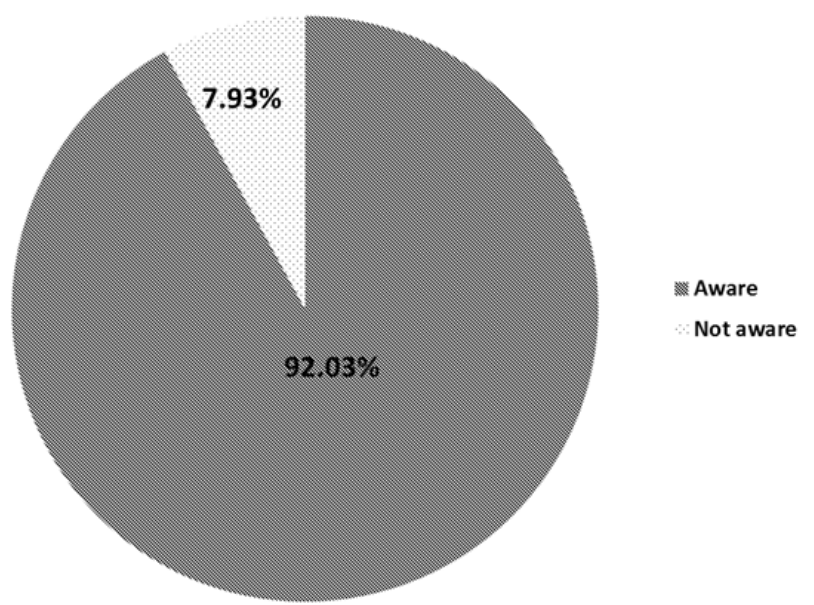

Figure 2. Graphical representation of amount of respondents who are and are not aware of the proposed graphic warnings on packets of cigarettes.

- All together $102(89.47 \%)$ of the respondents were of the view that the demonstrated pictorial warnings send a stronger message than the already existing warnings while $6(5.26 \%)$ disagreed and another 6 $(5.26 \%)$ were undecided on the matter.

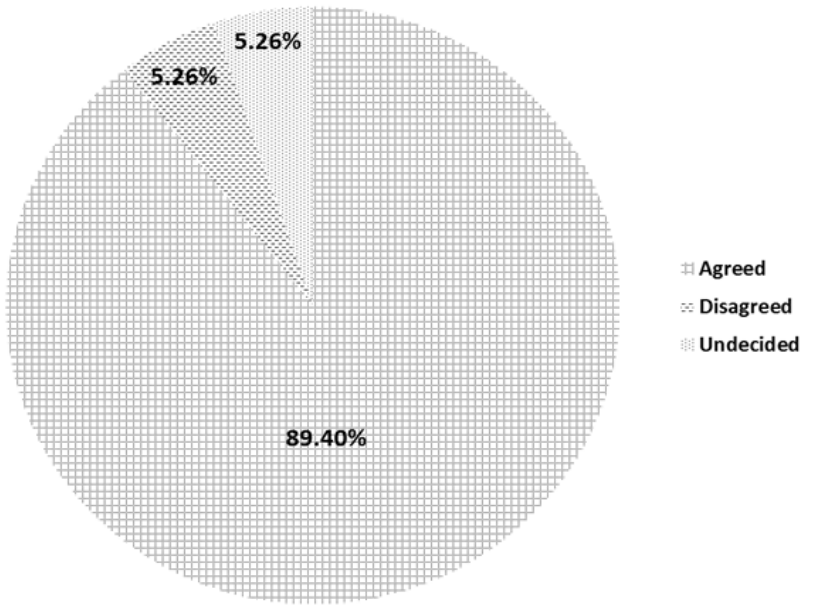

Figure 3. Graphical representation of the differences in perceptions among the respondents about efficacy of graphical warnings over already existing warning statements.
- Out of the respondents $87(76.31 \%)$ thought that the demonstrated pictorial warnings would have a negative impact on future smokers while $8(7.02 \%)$ disagreed and 19 (16.67\%) were undecided.

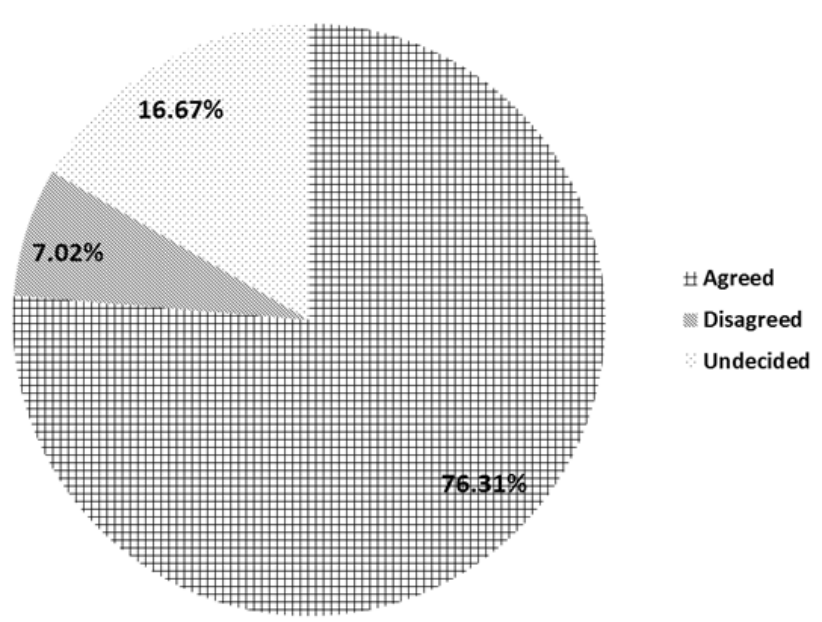

Figure 4. Graphical representation of the differences in perceptions among the respondents on whether the graphical warnings would have a negative impact on the future smokers.

- Overall $82(71.93 \%)$ of the respondents were of the view that that the demonstrated pictorial warnings would persuade the smokers to give up smoking while 17 (14.92\%) disagreed and $15(13.15 \%)$ were undecided.

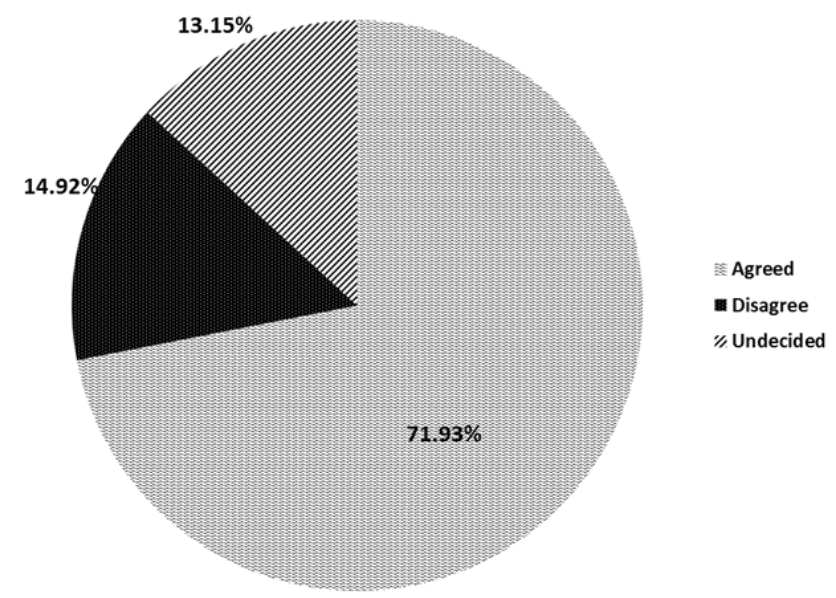

Figure 5. Graphical representation of differences in perception among respondents on whether the demonstrated pictorial warnings would persuade the smokers to quit smoking.

- Out of the 51 smokers that were interviewed $42(80.39 \%)$ thought that the demonstrated pictorial warnings caused a negative impact on their own smoking habits while $9(19.61 \%)$ disagreed. Furthermore $42(82.35 \%)$ of the smokers thought that the demonstrated pictorial warnings caused an urge in them to give up smoking while $9(17.65 \%)$ disagreed. 


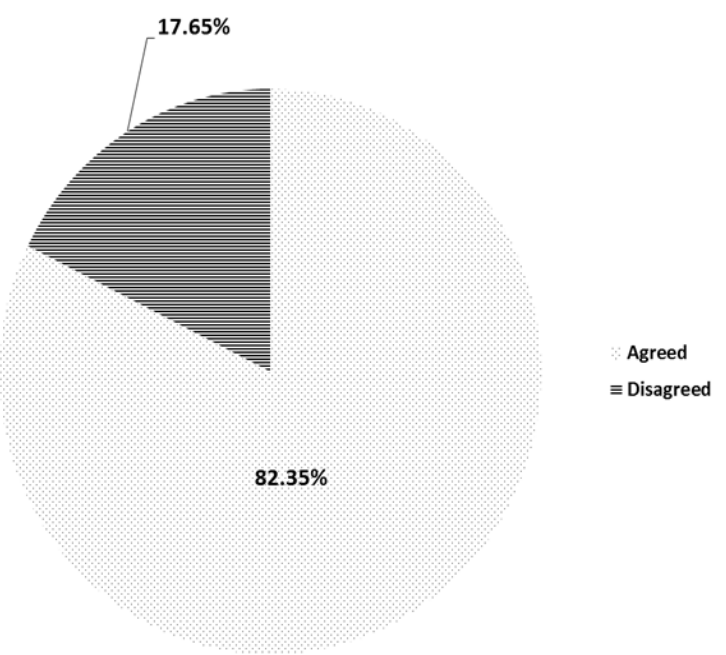

Figure 6. Graphical representation of difference in perception among smokers whether the demonstrated graphic warnings caused a negative impact on their own smoking habits.

3. Difference of attitudes towards proposed graphic warning between smokers and non-smokers

- Out of the 63 non-smokers 55 (87.3\%) was of the view that the demonstrated pictorial warnings send a stronger message than the already existing warnings while $47(92.15 \%)$ out of the 51 smokers interviewed shared the same view. There was no statistical significant difference between the two groups $(\mathrm{p}<0.05)$.

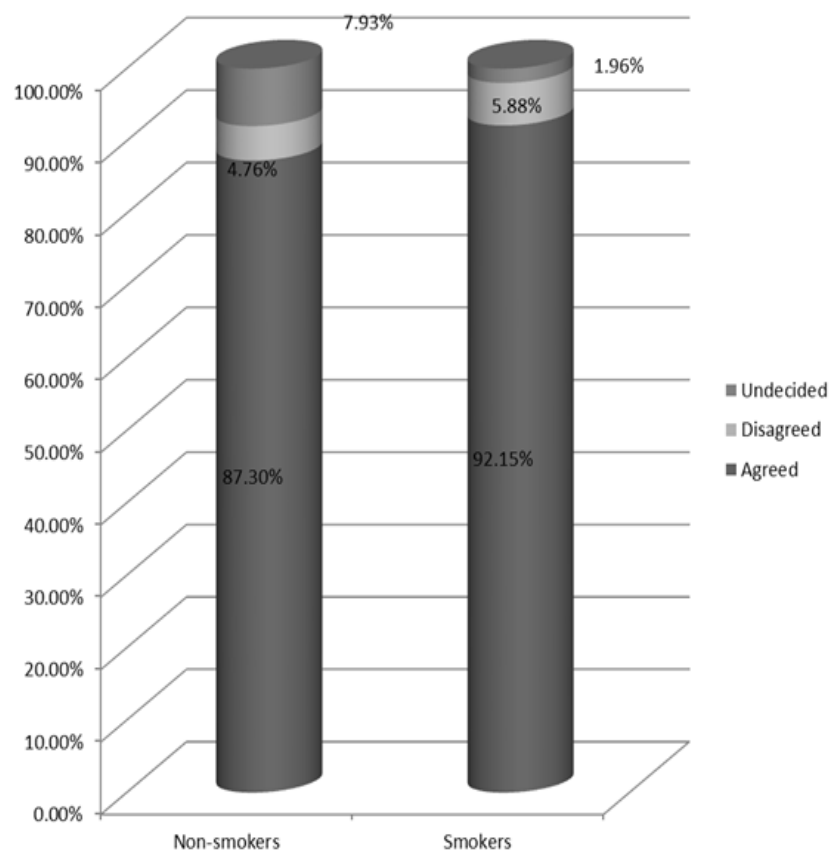

Figure 7. Graphical representation of the differences in perceptions among the non-smokers and smokers about efficacy of graphical warnings over already existing warning statements

- More smokers than non-smokers thought that the demonstrated pictorial warnings would have a negative impact on future smokers. Out of the 63 non-smokers, $43(68.25 \%)$ and $44(86.27 \%)$ out of 51 smokers thought that the demonstrated pictorial warnings would have a negative impact on future smokers. A statistically significant difference was observed between the two groups $(\mathrm{p}<0.05)$.

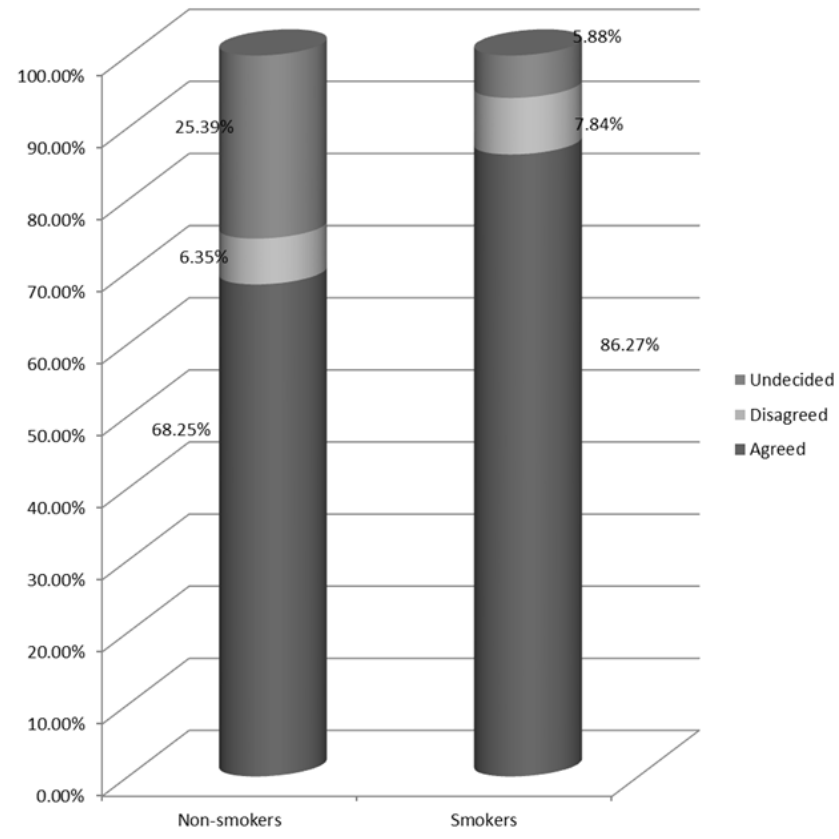

Figure 8. Graphical representation of the differences in perceptions among non-smokers and smokers on whether the graphical warnings would have a negative impact on the future smokers.

- Out of the non-smokers, $41(65.27 \%)$ and 41 of the smokers $(80.39 \%)$ answered positively that the demonstrated pictorial warnings would persuade the smokers to give up smoking. There was no statistically significant difference between the two groups $(\mathrm{p}<0.05)$.

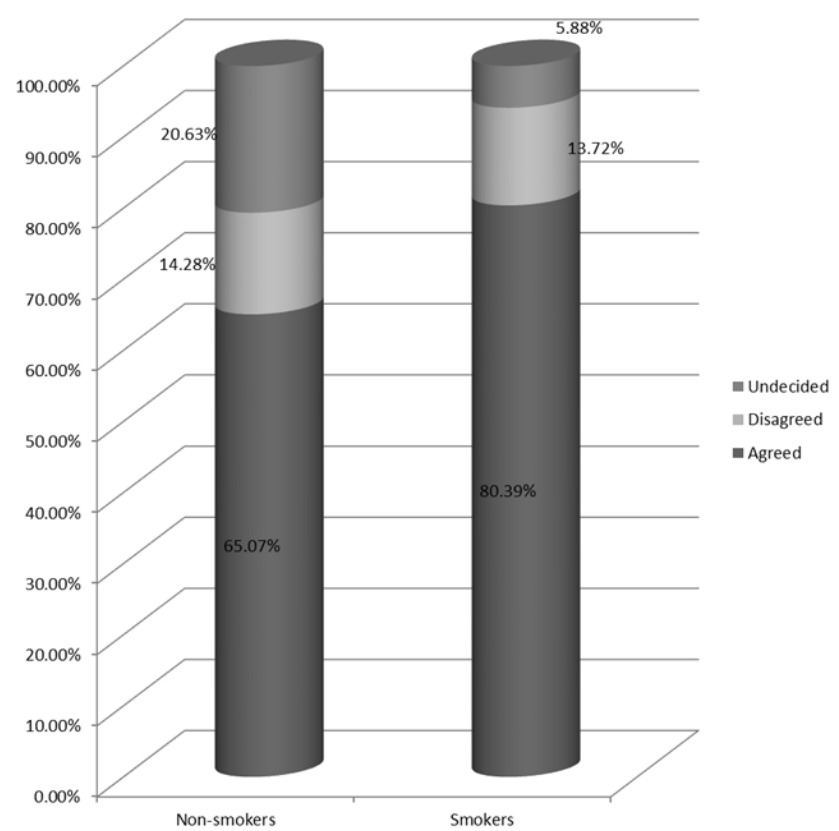

Figure 8. Graphical representation of differences in perception among non-smokers and smokers on whether the demonstrated pictorial warnings would persuade the smokers to quit smoking 


\section{Discussion}

Tobacco is the greatest single cause of preventable deaths globally according to WHO report, "Global Tobacco Epidemic" published in $2008^{(1)}$. Several countries have taken measures to control the consumption of tobacco with usage and sales restrictions and warning messages printed on packages. Sri Lanka's Supreme Court has ordered the country's leading tobacco product manufacturer, Ceylon Tobacco Company to cover 60 per cent of the surface area of the cigarette packs with graphic health warnings, 1 January 2015 onwards.

An institution based cross sectional descriptive and analytical study was carried out among the heath care workers stationed at the National Hospital of Sri Lanka. The study was carried out to assess the knowledge on existing printed warnings on packets of cigarettes, the knowledge and attitudes on proposed graphic warnings and compare the difference in attitudes towards proposed graphic warning between smokers and non-smokers. This study involved 119 participants who were selected randomly. Information was obtained by a self-administered questionnaire.

\section{Summary of the findings}

According to the study majority of the respondents were aware that there were already existing warning messages printed on packets of cigarettes. However, only a minority $(36.79 \%)$ of the sample could identify these particular warning messages. Majority of the sample population were already aware of the government's decision to include pictorial warnings on packets of cigarettes.

The majority of the respondents thought that the demonstrated pictorial warnings would send a stronger message than the already existing warnings, have a negative impact on future smokers and persuade the smokers to give up smoking. More smokers than non-smokers shared the views that that the demonstrated pictorial warnings would send a stronger message than the already existing warnings, have a negative impact on future smokers and persuade the smokers to give up smoking. The amount of smokers, who thought that the pictorial warnings would discourage the future smokers to take up smoking, was significantly more than the non-smokers who shared the same view.

Majority of the smokers thought that the demonstrated pictorial warnings caused a negative impact on their own smoking habits and would result in an urge to give up smoking.

\section{Comparison of the research findings with similar studies}

This study shows that majority were of the view that the demonstrated pictorial warnings send a stronger message than the already existing warnings. These results coincide with the results of the study in Australia conducted by R. Borland and D. Hill in $1997^{(1)}$ and the study carried by Silpasuwan $\mathrm{P}$, et all in Thailand ${ }^{(3)}$.

This study also shows that the majority of the participants thought that the pictorial warnings would discourage the future smokers to take up smoking. These results coincide with the study done in the United States in $2010^{(5)}$.

This study shows that more smokers than non-smokers endorsed the view that the proposed graphic designs would persuade the smokers to give up smoking. However a research conducted in 2011 by the Food and Drug Administration in the United States ${ }^{(4)}$ found out that more non-smokers than smokers endorsed the idea that the proposed graphic designs would persuade the smokers to give up smoking.

Local studies relevant to this research topic were not available at the time of the study.

\section{Implications}

Already existing warning texts on packets of cigarettes have not reached the majority of the target population. There is a high awareness of the proposed graphic warnings among the target population. Majority of the smokers and non-smokers endorse the view that the proposed graphic warnings would reach the public better and have an effective negative impact on the smoking habits of the public. Smokers in particular thought that graphic warnings could ignite contemplation in them. In the population such a shift in attitude could be a major impetus to reduce smoking rate.

\section{Limitations and Suggested Further Work}

Among smokers opinions could vary with the magnitude of addiction. This factor was not considered in this study. The magnitude of addiction of a subject correlates with the amount of cigarettes smoked per day. In the Sri Lankan setting the retail buyer does not receive a package of cigarettes unless a substantial amount of cigarettes are bought. This could result in smokers who smoke only a few cigarettes per day not receiving the packets of cigarettes which carry the proposed graphic warnings.

Although this study has reviewed the target population's purview of graphic warnings' impact on future smokers, it has not assessed the views shared by the actual prospective smokers of adolescent age group. This is seen as a major hiatus of this study by the authors.

The authors would like to suggest further research been included these particulars.

Retrospective research should be carried out after the introduction of the graphic warnings to assess their true impact smoking habits of the public.

\section{Conclusions and Recommendations}

\section{Conclusions}

- Majority of the study population are not aware of the pre-existing text only warning messages on packets of cigarettes.

- Majority of the study population share the view that the proposed graphic warnings would have a 
negative impact on smoking habits of the public.

- Majority of the smokers endorsed the view that the proposed graphic warnings would lead to contemplation of smoking.

Recommendations

- These findings provide strong support for introducing graphic warnings.

- Proposed graphic warnings will most likely change the smoking habits of the public. However retrospective research should be carried out after the introduction of the graphic warnings to assess its true impact.

- Future studies should focus on how the smokers' perceptions and attitudes towards the proposed graphic warnings vary with the amount of cigarettes smoked per day.

- Members of the adolescent age group should be involved in assessing the impact of proposed graphic warnings exerted on prospective smokers.

\section{REFERENCES}

[1] World Health Organization, 2008. WHO Report on the Global Tobacco Epidemic 2008: The MPOWER Package (Documents for Sale). 1 Pck Edition. World Health Organization.

[2] Centers for Disease Control and Prevention (CDC), April 2002. Annual smoking-attributable mortality, years of potential life lost, and economic costs - United States, 1995-1999. MMWR Morb. Mortal. Wkly. Rep. 51

[3] ADIC, Alcohol and Drug Information Centre, 2012. Spot Survey - December 2012 Trends in Tobacco Consumption. Colombo 05, Sri Lanka: ADIC.

[4] Engelgau, Michael; Okamoto, Kyoko; Navaratne, Kumari Vinodhani; Gopalan, Sundararajan. 2010. Prevention and Control of Selected Chronic NCDs in Sri Lanka: Policy Options and Action. World Bank, Washington, DC.

[5] Ceylon Tobacco Company PLC v. Hon. Maithripala Sirisena, Minister of Health et. al. C.A. Application No.336/2012 February 22, 2013 Court of Appeal of Sri Lanka

[6] World Health Organization, 2008. The Global Burden of Disease: 2004 Update. 1 Edition. World Health Organization.

[7] World Health Organization, (2008). WHO Framework Convention on Tobacco Control. In WHO Framework Convention on Tobacco Control. Geneva, 21st May. Geneva: WHO. 04-30

[8] Adoption of Framework Convention on Tobacco Control. American Journal of International Law, 97/3, 689-691.

[9] Regulation Amending the Tobacco Products (Labelling and Packaging) Regulations, No. 01 of 2012, Parliament of Democratic Socialist Republic of Sri Lanka, Gazette Extraordinary No. $1797 / 22$ of $15^{\text {th }}$ February 2013.
[10] Parliament of Sri Lanka - News. 2014. Parliament of Sri Lanka - News. [ONLINE] Available at: http://www.parliament.lk/n ews-en/view/871. [Accessed 07 May 2014].

[11] Supreme Court orders manufacturer to include graphic health warnings. [ONLINE] Availableat:http://www.tobaccojournal .com/Supreme_Court_orders_manufacturer_to_include_grap hic health_warnings. $\overline{5} 2504 . \overline{0} . \mathrm{html}$. [Accessed 22 September 2014].

[12] Borland R, Hill D, 1997. Initial Impact of the new Australian tobacco health warnings of knowledge and beliefs. Tobacco control 1997; 6: 317-325.

[13] Yong H, Fong GT, Driezen P, Borland R, Quah ACK, Sirirassamee B, Hamann S, Omar M 2013. Adult Smokers' Reactions to Pictorial Health Warning Labels on Cigarette Packs in Thailand and Moderating Effects of Type of Cigarette Smoked: Findings From the International Tobacco Control Southeast Asia Survey. Nicotine Tob Res. Aug 2013; 15(8):1339-1347.

[14] SilpasuwanHYPERLINK

"/pubmed?term=Silpasuwan\%20P\%5BAuthor\%5D\&cauthor $=$ true\&cauthor uid=18556866" P, YaowalukHYPERLINK "/pubmed?term $=$ Yaowaluk\%20N\%5BAuthor\%5D\&cauthor $=$ true\&cauthor uid $=18556866 " \mathrm{~N}$,

ViwatwongkasemHYPERLINK

"/pubmed?term=Viwatwongkasem\%20C\%5BAuthor\%5D\& cauthor=true\&cauthor_uid=18556866" C,

SatitvipaweeHYPERLINK

"/pubmed?term=Satitvipawee\%20P\%5BAuthor\%5D\&cauth or=true\&cauthor_uid=18556866" P,

SirichotiratanaHYYPERLINK

"/pubmed?term=Sirichotiratana\%20N\%5BAuthor\%5D\&caut hor=true\&cauthor uid $=18556866 " \mathrm{~N}$, SujiraratHYPERLINK "/pubmed?term=Sujirarat\%20D\%5BAuthor\%5D\&cauthor=t rue\&cauthor_uid=18556866" D. Potential effectiveness of health warning labels among employees in Thailand. J Med Assoc Thai, Apr 2008; 91(4):551-8.

[15] HYPERLINK

"/search?author $1=$ Andrea + C. + Villanti\&sortspec $=$ date \&sub mit=Submit"Villanti C, HYPERLINK

"/search?author1=Jennifer+Cantrell\&sortspec $=$ date \&submit =Submit"Jennifer C, Pearson JL, HYPERLINK

"/search?author $1=$ Donna + M. + Vallone\&sortspec $=$ date\&sub mit=SubmitHYPERLINK

"/search?author $1=$ Donna + M. + Vallone\&sortspec $=$ date\&sub mit=Submit"Vallone D, HYPERLINK

"/search?author1=Jessica+M.+Rath\&sortspec=date\&submit $=$ Submit"Rath JM. Perceptions and Perceived Impact of Graphic Cigarette Health Warning Labels on Smoking Behavior Among U.S. Young Adults, Nicotine Tob Res. Apr 2014;16(4):469-77.

[16] Pepper JK, Cameron LD, Reiter PL, McRee AL, Brewer NT. Non-Smoking Male Adolescents' Reactions to Cigarette Warnings. PLoS ONE 8(8): e65533.doi:10.1371/journal.pon e.0065533

[17] United Kingdom | Tobacco Labelling Regulations. 2014. United Kingdom | Tobacco Labelling Regulations. [ONLINE] Available at:http://www.tobaccolabels.ca/countries/united-ki ngdom/. [Accessed 24 September 2014]. 